7. Reprod. Fert. (1973) 33, 1-9

\title{
CHEMICAL SYMPATHECTOMY OF THE RABBIT OVIDUCT USING 6-HYDROXYDOPAMINE
}

\author{
C. A. EDDY AND D. L. BLACK \\ Laboratory for Reproductive Physiology, Department of Veterinary and Animal Sciences, \\ University of Massachusetts, Amherst, Massachusetts, U.S.A.
}

(Received 1st February 1972)

Summary. Chemical sympathectomy followed transluminal perfusion of the rabbit oviduct with 6-hydroxydopamine (6-OHDA). Histofluorescence studies 1 week after perfusion revealed an absence of formaldehyde-norepinephrine $(\mathrm{NE})$-induced fluorescence in treated oviducts while contralateral control oviducts which were not perfused exhibited normal fluorescence. Endogenous NE concentrations of treated and control oviducts and their associated uterine horns were measured biochemically 1 week after perfusion. A dose-dependent decrease in NE was demonstrated in 6-OHDA-perfused oviducts. By contrast, contralateral control oviducts and both uterine horns exhibited no significant decrease in endogenous NE until doses of 6-OHDA in excess of those required for functional denervation were perfused through treated oviducts.

\section{INTRODUCTION}

The incomplete understanding of the rôle of the sympathetic nervous system in the physiology of the mammalian oviduct is due largely to the lack of an effective technique for achieving an efficient, controlled sympathectomy. The use of norepinephrine(NE)-depleting drugs to produce a pharmacological denervation of the oviduct also causes alteration of function in organs unrelated to the oviduct. Similarly, the use of receptor blockers to achieve functional denervation suffers the same shortcoming.

Attempts to achieve a specific denervation of the oviducts have generally involved a surgical approach. Surgical sympathectomy of the oviduct, however, requires extensive transection and probably leads to parasympathectomy as well. In addition, anatomical variation between animals leads to inconsistent results.

Recent studies have shown that 6-hydroxydopamine (6-OHDA) is capable of inducing selective degeneration of terminal adrenergic nerve endings without affecting cholinergic nerve terminals (Tranzer \& Thoenen, 1968; Knyihar, Ristovsky, Kalman \& Csillik, 1969; Bennett, Burnstock, Cobb \& Malmfors, 1970; de Champlain \& Nadeau, 1971). Depletion of endogenous NE is rapid and complete when sufficient quantities of 6-OHDA are administered. Systemically administered 6-OHDA is taken up by the adrenergic nerve endings of virtually every tissue resulting in a drug-induced sympathectomy (Malmfors \& Sachs, 1968). It appears that control of the drug's action can be achieved by controlling its tissue distribution. 
Preliminary studies in this laboratory demonstrated the ability of the rabbit oviduct to absorb 6-OHDA from the tubal lumen. The extent of the resulting denervation was dependent upon drug concentration and time spent in the oviduct. Small doses placed in the ligated oviduct for short periods of time led to fairly localized denervation while large amounts present for extended periods led to extensive systemic denervation.

Further study showed that better control of 6-OHDA uptake could be achieved by perfusing the drug through the oviduct. By varying the concentration of drug perfused, an optimum uptake of 6-OHDA sufficient to cause total denervation of the oviduct but insufficient to produce significant systemic effects could be achieved. The present paper describes such a technique for inducing controlled chemical denervation of individual oviducts.

\section{MATERIALS AND METHODS}

Thirty adult, oestrous, virgin rabbits of mixed breed, weighing 1.75 to $3.00 \mathrm{~kg}$, were used. They were separated into six groups of five animals each. The hydrobromide of 6-OHDA (Sigma Chemical Co. or Regis Chemical Co.) was dissolved in physiological saline containing ascorbic acid $(1 \mathrm{mg} / \mathrm{ml})$. Single oviducts in all animals were perfused with $400 \mu 1$ ascorbic saline containing a calculated amount of 6-OHDA (Table 1).

Table 1. Dosage schedule of 6-OHDA administration

\begin{tabular}{|c|c|c|c|c|c|c|}
\hline & \multicolumn{6}{|c|}{ Group } \\
\hline & 1 & 2 & 3 & 4 & 5 & 6 \\
\hline $\begin{array}{l}\text { No. of rabbits } \\
\text { Concentration of 6-OHDA }(\mathrm{mg} / \mathrm{ml}) \\
\text { Total amount of } 6-\mathrm{OHDA}(\mathrm{mg})\end{array}$ & $\begin{array}{l}5 \\
0 \cdot 00 \\
0 \cdot 00\end{array}$ & $\begin{array}{l}5 \\
1 \cdot 25 \\
0 \cdot 50\end{array}$ & $\begin{array}{l}5 \\
2 \cdot 50 \\
1 \cdot 00\end{array}$ & $\begin{array}{r}5 \\
12 \cdot 5 \\
5 \cdot 0\end{array}$ & $\begin{array}{c}5 \\
25 \cdot 0 \\
10 \cdot 0\end{array}$ & $\begin{array}{c}5 \\
50 \cdot 0 \\
20 \cdot 0\end{array}$ \\
\hline
\end{tabular}

For abbreviations, see text.

\section{Perfusion technique}

Animals were anaesthetized with sodium pentabarbital $(32.0 \mathrm{mg} / \mathrm{kg}$ intravenously) and subjected to laparotomy. A $32 \cdot 0-\mathrm{cm}$ length of $\mathrm{PE} 60$ polyethylene tubing (i.d. $0.030 \mathrm{in}$ and o.d. 0.048 in., Clay Adams) connected to a 2-ml syringe containing the 6-OHDA solution was introduced into a uterine horn and passed through the uterotubal junction. The tubing was anchored in the uterine end of the isthmus and a ligature applied around the uterotubal junction to prevent reflux of 6-OHDA into the uterus. A $20 \cdot 0-\mathrm{cm}$ length of similar tubing was then passed through the infundibulum and ligated in place in the distal portion of the ampulla to serve as a vent. The 2-ml syringe was placed in a Harvard Model 901 infusion/withdrawal pump and the oviduct was perfused at a rate of $7 \mu \mathrm{l} / \mathrm{min}$ in the ovarian direction. Following the perfusion of $400 \mu \mathrm{l}$ 6 -OHDA, the oviduct was washed out by perfusion with $400 \mu \mathrm{l}$ ascorbic saline at a rate of $20 \mu \mathrm{l} / \mathrm{min}$. Control group animals were similarly perfused with 
ascorbic saline alone. Contralateral oviducts not subjected to perfusion served as controls for the NE assays.

Following perfusion, the laparatomy incisions were sutured and the animals were returned to individual cages. Endogenous NE levels of treated and contralateral control oviducts were determined biochemically (Maickel, Cox, Saillant \& Miller, 1968) and histofluorometrically (Falck \& Owman, 1965) 1 week later.

\section{Biochemical assay}

Animals were killed with an overdose of anaesthetic and the oviducts were quickly removed and placed on crushed ice. After trimming away all excess tissue, each oviduct was divided into five equal segments which were blotted and weighed. Individual pieces were homogenized with a hand glass homogenizer and the NE was extracted, oxidized, and analysed spectrophotofluorometrically after the method of Maickel et al. (1968), with the following modifications: (1) the amount of $0.1 \mathrm{~N}-\mathrm{HCl}$ used for aqueous extraction of $\mathrm{NE}$ was doubled (to $0.8 \mathrm{ml}$ ); (2) the aliquot of $0.1 \mathrm{~N}-\mathrm{HCl}$ aqueous phase used for oxidation to NE photofluor was $0.5 \mathrm{ml}$ (instead of $0.1 \mathrm{ml}$ ); (3) the recovery of NE was monitored, using $\left[{ }^{3} \mathrm{H}\right] \mathrm{NE}$ added to the tissues after homogenization.

Average recovery of $\mathrm{NE}$ for the complete procedure was $97 \%$ for standards and $74 \%$ for tissue. Oviduct NE values were uncorrected for non-specific tissue fluorescence. Pretreatment with $10.0 \mathrm{mg}$ Reserpine $36 \mathrm{hr}$ and $18 \mathrm{hr}$ before assay was found to give readings which were 11 to $13 \%$ those of control readings. Levels of $\mathrm{NE}$ were computed both for individual segments and for whole oviducts and were expressed as $\mu \mathrm{g} \mathrm{NE} / \mathrm{g}$ tissue. In the latter case, the NE concentration was computed as the average of the concentrations of the five segments composing the oviduct.

\section{Histofluorescence}

Sections of trimmed oviduct were prepared for fluorescence microscopy according to the technique of Falck \& Hillarp (Falck \& Owman, 1965). Tissues were quickly frozen in liquid nitrogen-cooled isopentane and transferred to a Virtis freeze dryer. Following a 3- to 5-day period of desiccation under vacuum at $-35^{\circ} \mathrm{C}$, the dehydrated tissue was exposed to paraformaldehyde vapour at optimum humidity for $1 \mathrm{hr}$ at $80^{\circ} \mathrm{C}$. The tissue was then vacuumembedded in paraffin wax and 9- $\mu \mathrm{m}$ sections were cut and mounted in Entellan for fluorescence microscopy.

\section{Histology}

In order to rule out perfusion- and drug-induced trauma, random portions of treated and control oviducts were fixed in Bouin's fluid and embedded in paraffin wax. Sections of 5 to $7 \mu \mathrm{m}$ were stained with haematoxylin and eosin and viewed under light microscopy (Guyer, 1953).

The statistical significance between control and 6-OHDA-treated oviducts was calculated by analysis of variance and Duncan's New Multiple Range Test (Steel \& Torrie, 1960). 
RESULTS

Biochemical assay

The NE content of rabbit oviducts was measured within 1 week after transluminal perfusion with 6-OHDA. Reduction of NE in treated oviducts was observed throughout the dose range used (Table 2). The effect of 6-OHDA,

Table 2. Effect of 6-OHDA on NE concentration of rabbit oviducts

\begin{tabular}{|c|c|c|c|}
\hline \multirow{2}{*}{$\begin{array}{c}\text { Dose } \\
\text { (mg/oviduct) }\end{array}$} & \multicolumn{2}{|c|}{$\begin{array}{c}\text { NE Concentration } \\
(\mu g / g \pm S . E .)\end{array}$} & \multirow[t]{2}{*}{$\%$ Decrease } \\
\hline & Control & 6-OHDA & \\
\hline $\begin{array}{l}0 \\
0 \cdot 5 \\
1 \cdot 0 \\
5 \cdot 0 \\
10 \cdot 0 \\
20 \cdot 0\end{array}$ & $\begin{array}{l}5.59 \pm 0.82 \\
3.18 \pm 0.62 \\
7.07 \pm 1.40 \\
6.41 \pm 1.16 \\
3.77 \pm 1.00 \\
2.17 \pm 0.45\end{array}$ & $\begin{array}{l}5.47 \pm 0.95 \\
2.26 \pm 0.62 \\
3.79 \pm 0.76 \\
1.91 \pm 0.22 \\
1.19 \pm 0.16 \\
1.15 \pm 0.11\end{array}$ & $\begin{array}{c}3 \cdot 6 \pm 2 \cdot 1 \\
28 \cdot 8 \pm 2 \cdot 9 * * \\
46 \cdot 3 \pm 5 \cdot 9 * * \\
69 \cdot 8 \pm 2 \cdot 9^{* *} \\
68 \cdot 2 \pm 4 \cdot 3^{* *} \\
44 \cdot 5 \pm 8 \cdot 9^{* *}\end{array}$ \\
\hline
\end{tabular}

For abbreviations, see text.

** $P<0.01$.

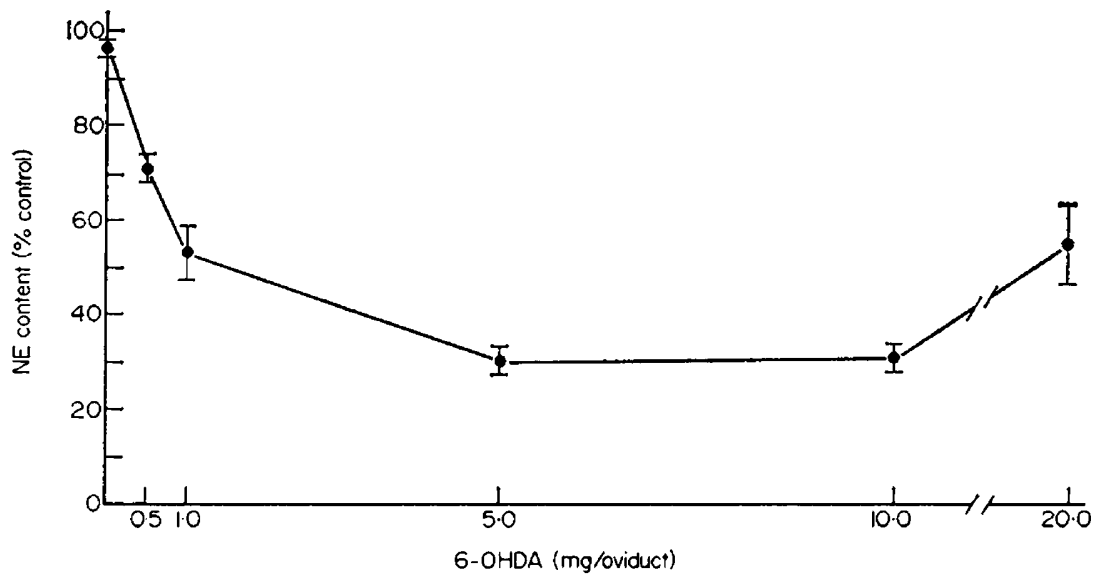

TExT-FIG. 1. Percentage change in the NE content of rabbit oviducts following treatment with 6-OHDA. Each point is the mean percentage change ( \pm S.E.M.) between 6-OHDAperfused oviducts and the respective contralateral control oviducts of five does.

expressed as the percentage difference between perfused and contralateral control oviducts, is shown in Text-fig. 1. The lowest dose of 6-OHDA ( 0.5 $\mathrm{mg} /$ oviduct) caused an average decrease of $29 \%$ in NE content while the highest dose $(20 \mathrm{mg} /$ oviduct) caused a $44 \%$ decrease. By contrast, the intermediate doses ( 1.0 to $10.0 \mathrm{mg} /$ oviduct) produced a marked reduction in NE content ranging from 46 to $70 \%$, the largest decrease being in response to the intermediate dose of $5.0 \mathrm{mg} /$ oviduct. The reverse in response to higher doses is probably due to an increased systemic effect which lowers control oviduct NE levels, reducing the apparent NE depletion of treated oviducts. 
Because there might be a systemic effect and subsequent reduction of $\mathrm{NE}$ in the control oviducts (not perfused) of 6-OHDA-treated rabbits, oviducts perfused with 6-OHDA were contrasted with the oviducts perfused with ascorbic-saline of the control group; contralateral control oviducts (not perfused) were contrasted with the corresponding control oviducts of the ascorbicsaline group (Table 3, Text-fig. 2).

Table 3. Percentage decrease in the NE content of 6-OHDA-perfused and contralateral control oviducts compared to respective ascorbic saline-perfused and contralateral control oviducts in rabbits

\begin{tabular}{c|c|c}
\hline $\begin{array}{c}\text { Dose } \\
\text { (mgloviduct })\end{array}$ & $\begin{array}{c}\text { Control } \\
\text { (not perfused })\end{array}$ & 6 -OHDA-perfused \\
\hline 0 & 0 & 0 \\
$0 \cdot 5$ & $37 \cdot 1 \pm 10 \cdot 3$ & $53 \cdot 3 \pm 8 \cdot 1^{* *}$ \\
$1 \cdot 0$ & $+34 \cdot 9 \pm 29 \cdot 0$ & $24 \cdot 0 \pm 17 \cdot 5^{\mathrm{N} . s .}$ \\
$5 \cdot 0$ & $+25 \cdot 6 \pm 23 \cdot 4$ & $62 \cdot 4 \pm 4 \cdot 7^{*}$ \\
$10 \cdot 0$ & $27 \cdot 9 \pm 8 \cdot 5$ & $74 \cdot 3 \pm 6 \cdot 5^{* *}$ \\
$20 \cdot 0$ & $56 \cdot 1 \pm 10 \cdot 5 *$ & $75 \cdot 3 \pm 5 \cdot 8^{* *}$ \\
\hline
\end{tabular}

N.S. = not significant. For other abbreviations, see text.

$* P<0.05 ; * * P<0.01 ; \dagger$ Increase in NE.

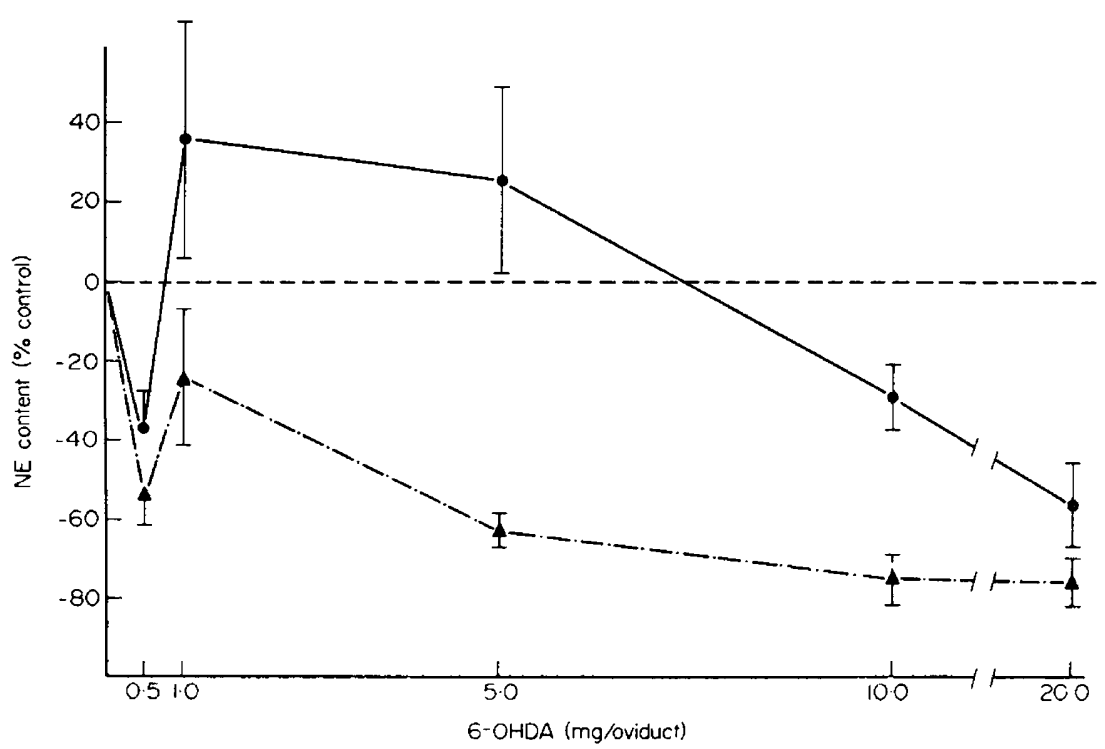

TExT-Fig. 2. Percentage change in the NE content of 6-OHDA-perfused $(\Delta)$ and contralateral control $(\bullet)$ oviducts. Each point is the mean $( \pm$ S.E.M.) of five observations (see text for details).

Perfusion with the lowest dose of 6-OHDA $(0.5 \mathrm{mg} /$ oviduct) caused an average decrease of $53 \%$ in NE content compared to that of the oviducts of the control group perfused with ascorbic saline. Doubling this dose $(1.0 \mathrm{mg} /$ oviduct $)$ produced approximately half the depletion $(24 \%)$ while the three highest doses 
(5.0 to $20.0 \mathrm{mg} /$ oviduct) produced a marked reduction of NE content, ranging from 62 to $75 \%$ of the control group values. The largest reduction resulted from the largest dose of 6-OHDA.

In animals treated with $0.5 \mathrm{mg} 6-\mathrm{OHDA} /$ oviduct, control oviducts showed a rather large average reduction in NE content of $37 \%$. By contrast, increases of 35 and $26 \%$ above control group values were seen in the 1.0 and $5.0 \mathrm{mg} /$ oviduct groups, respectively. Depletion in NE, however, was again seen in the 10.0 and $20.0 \mathrm{mg} /$ oviduct groups as increasing systemic effects produced a 28 and $56 \%$ reduction in NE content, respectively (Text-fig. 2).

The NE-depleting effect of 6-OHDA upon various segments of the oviduct, expressed as the percentage change from the appropriate control group segment, is shown in Table 4.

Table 4. Percentage NE depletion in rabbit oviduct and uterine tissue in response to 6-OHDA

\begin{tabular}{|c|c|c|c|c|c|}
\hline \multirow{2}{*}{ Tissue } & \multicolumn{5}{|c|}{ Dose of 6-OHDA/oviduct } \\
\hline & $0.5 \mathrm{mg}$ & $1.0 \mathrm{mg}$ & $5 \cdot 0 \mathrm{mg}$ & $10.0 \mathrm{mg}$ & $20 \cdot 0 \mathrm{mg}$ \\
\hline \multirow{2}{*}{$\begin{array}{c}\text { Oviduct } \\
\text { segment } \\
1 \\
2 \\
3 \\
4 \\
5\end{array}$} & \multicolumn{5}{|c|}{ Control (not perfused) } \\
\hline & $\begin{array}{l}\uparrow 8 \cdot 2 \pm 18 \cdot 1 \\
22 \cdot 4 \pm 22 \cdot 6 \\
28 \cdot 2 \pm 20 \cdot 0 \\
41 \cdot 0 \pm 8 \cdot 1 \\
42 \cdot 2 \pm 9 \cdot 8 *\end{array}$ & $\begin{array}{l}+63.9 \pm 52 \cdot 2 \\
+90 \cdot 0 \pm 58 \cdot 7 \\
+55.8 \pm 44 \cdot 0 \\
+41.9 \pm 23 \cdot 0 \\
+16 \cdot 1 \pm 19.8\end{array}$ & $\begin{array}{l}+47.6 \pm 29 \cdot 7 \\
+66.4 \pm 40 \cdot 5 \\
+49.4 \pm 47 \cdot 0 \\
+18.7 \pm 25.4 \\
+11.7 \pm 12.8\end{array}$ & $\begin{array}{l}44 \cdot 6 \pm 9 \cdot 9 \\
41 \cdot 2 \pm 7 \cdot 7 \\
22 \cdot 7 \pm 24 \cdot 2 \\
26 \cdot 4 \pm 6 \cdot 8 \\
12 \cdot 8 \pm 11 \cdot 3\end{array}$ & $\begin{array}{l}32 \cdot 9 \pm 24 \cdot 4 \\
52 \cdot 1 \pm 19 \cdot 1 \\
60 \cdot 2 \pm 11 \cdot 8 \\
60 \cdot 4 \pm 9 \cdot 7 * \\
50 \cdot 7 \pm 11 \cdot 1^{*}\end{array}$ \\
\hline Uterus & $2 \cdot 9 \pm 20 \cdot 0$ & $63 \cdot 8 \pm 37 \cdot 2$ & $21 \cdot 0 \pm 41 \cdot 3$ & $5 \cdot 9 \pm 38 \cdot 8$ & $16 \cdot 0 \pm 32 \cdot 8$ \\
\hline \multirow{2}{*}{$\begin{array}{c}\text { Oviduct } \\
\text { segment } \\
1 \\
2 \\
3 \\
4 \\
5\end{array}$} & \multicolumn{5}{|c|}{ Perfused } \\
\hline & $\begin{array}{l}32 \cdot 5 \pm 15 \cdot 9 \\
36 \cdot 2 \pm 18 \cdot 8 \\
47 \cdot 7 \pm 10 \cdot 0^{* *} \\
49 \cdot 0 \pm 8 \cdot 3^{* *} \\
77 \cdot 7 \pm 8 \cdot 4^{* *}\end{array}$ & $\begin{array}{c}+40 \cdot 5 \pm 27 \cdot 0 \\
+28 \cdot 2 \pm 28 \cdot 2 \\
5 \cdot 5 \pm 24 \cdot 5 \\
26 \cdot 4 \pm 18 \cdot 5 \\
56 \cdot 7 \pm 12 \cdot 7 * *\end{array}$ & $\begin{array}{l}18 \cdot 1 \pm 13 \cdot 7 \\
47 \cdot 8 \pm 5 \cdot 1^{* *} \\
64 \cdot 7 \pm 5 \cdot 4^{* *} \\
69 \cdot 1 \pm 5 \cdot 0^{* *} \\
68 \cdot 1 \pm 7 \cdot 8^{* *}\end{array}$ & $\begin{array}{l}46 \cdot 0 \pm 9 \cdot 6 \\
73 \cdot 4 \pm 6 \cdot 5^{* *} \\
80 \cdot 0 \pm 3 \cdot 7^{* *} \\
76 \cdot 4 \pm 7 \cdot 5^{* *} \\
72 \cdot 4 \pm 12 \cdot 3^{* *}\end{array}$ & $\begin{array}{l}33 \cdot 9 \pm 17 \cdot 4 \\
68 \cdot 1 \pm 10 \cdot 2^{* *} \\
78 \cdot 6 \pm 7 \cdot 1^{* *} \\
80 \cdot 8 \pm 5 \cdot 5^{* *} \\
77 \cdot 7 \pm 4 \cdot 1^{* *}\end{array}$ \\
\hline Uterus & $3 \cdot 5 \pm 19 \cdot 9$ & $34 \cdot 9 \pm 18 \cdot 9$ & $26 \cdot 3 \pm 39 \cdot 0$ & $22 \cdot 5 \pm 17 \cdot 5$ & $38 \cdot 0 \pm 14 \cdot 2$ \\
\hline
\end{tabular}

For abbreviations, see text. Segment 1 -nearest the ovary; Segment 5 -nearest the uterine horn.

* $P<0.05 ;{ }^{* *} P<0.01$; $\dagger$ Increase in NE.

The sensitivity of the oviduct to 6-OHDA was found to increase in a uterine direction. Within the dose range administered, 6-OHDA failed to decrease NE levels significantly in Segment 1 of the perfused oviducts. Increased sensitivity in those segments closer to the uterus led to highly significant decreases in NE content in Segments 2 to 5 . By contrast, most segments of control oviducts were not significantly affected by 6-OHDA. Significant systemic effects were seen only in Segment 4 of the $20.0 \mathrm{mg} /$ oviduct group and in Segment 5 of the 0.5 and $20 \cdot 0 \mathrm{mg} /$ oviduct groups.

Single segments from uterine horns associated with both perfused and control (not perfused) oviducts were analysed biochemically for the presence of NE using the same procedure as employed with oviduct tissue (Table 4). The response pattern of both uterine horns was found to be qualitatively similar to 


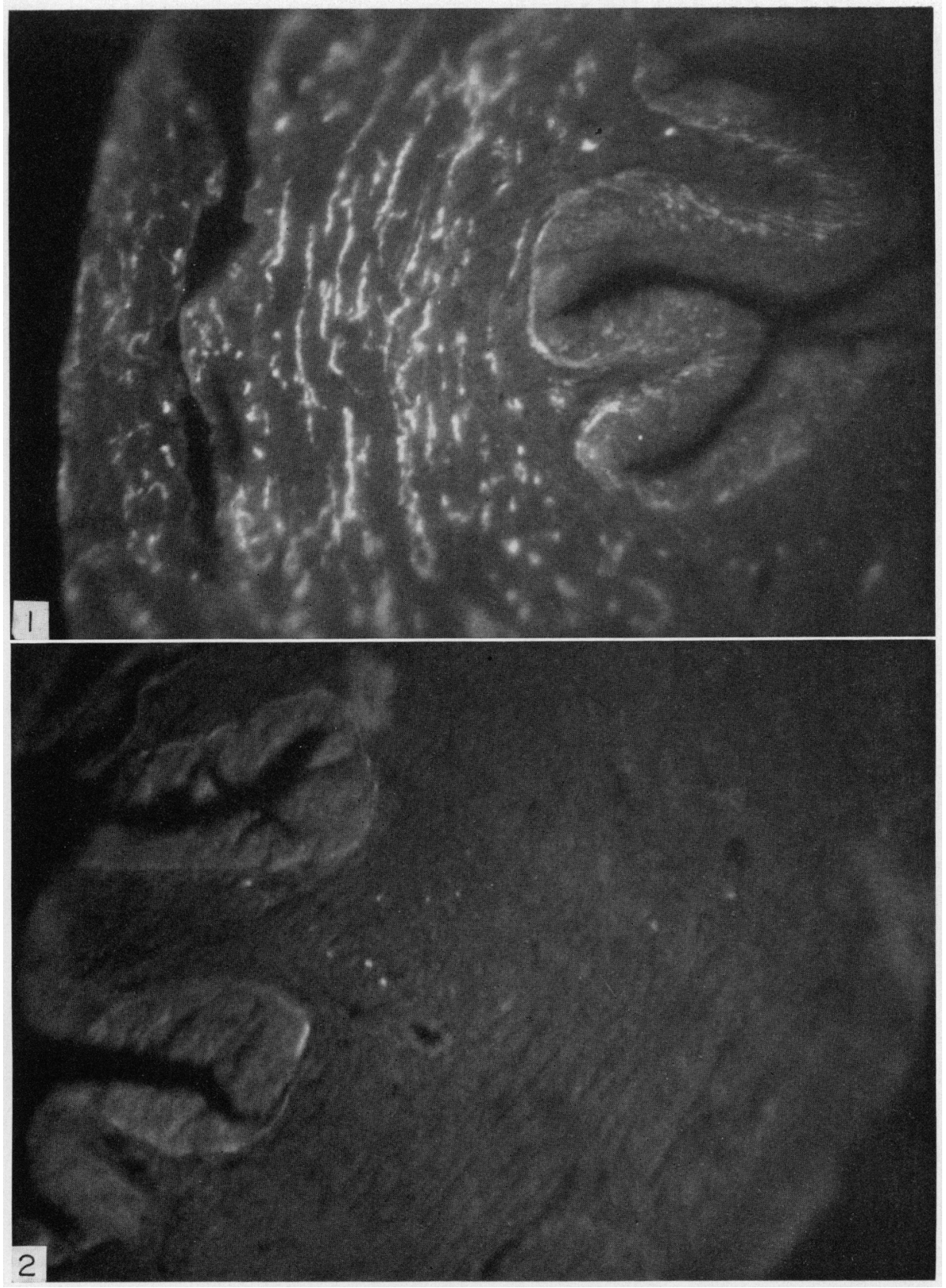

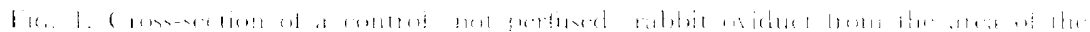

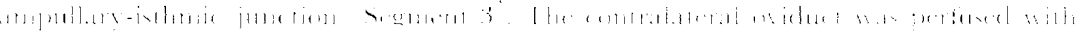

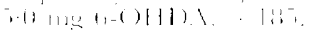

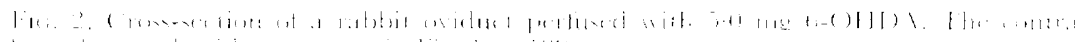

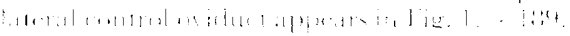


that of oviduct tissue which had not been perfused. Levels of NE were not significantly affected in either group throughout the dose range of 6-OHDA used.

\section{Histofluorescence}

Histofluorescent observation of the adrenergic innervation of control and perfused oviducts generally correlated with the results obtained from the biochemical assay. The lowest dose of 6 -OHDA $(0.5 \mathrm{mg} /$ oviduct) produced a moderate decrease in fluorescence in both perfused and control oviducts which was quantitatively indistinguishable. Normal, profuse, well-defined fluorescence was seen in control oviducts of the 1.0 and $5.0 \mathrm{mg} /$ oviduct groups (Pl. 1, Fig. 1). By contrast, oviducts perfused with $1.0 \mathrm{mg}$ 6-OHDA exhibited sparse, weak fluorescence and those perfused with $5.0 \mathrm{mg}$ 6-OHDA were essentially devoid of fluorescence (Pl. 1, Fig. 2). Control oviducts of the $10.0 \mathrm{mg} /$ oviduct group exhibited extensive fluorescence, though this lacked the usual crispness seen in oviducts of the control group. Fluorescence was absent from corresponding perfused oviducts. Perfusion with $20.0 \mathrm{mg}$ 6-OHDA severely depleted fluorescence in control oviducts and led to its absence in treated oviducts.

\section{Histology}

Histological findings revealed no disruptive effect, either mechanical or chemical, resulting from the perfusion procedure.

\section{DISCUSSION}

It has been shown that 6-OHDA produces a marked and prolonged depletion of NE after systemic administration (Tranzer \& Thoenen, 1968; Mueller, Thoenen \& Axelrod, 1969; Goldman \& Jacobowitz, 1971; de Champlain \& Nadeau, 1971). In the present study, a similar depletion obtained by perfusing 6-OHDA through the tubal lumen of the oviduct has been demonstrated. Unlike systemically administered 6-OHDA which produces widespread depletion of NE, transluminally perfused 6-OHDA, particularly within the 1.0to $5 \cdot 0-\mathrm{mg} /$ oviduct dose range, depletes only the perfused oviduct. As the dose of 6-OHDA perfused through the treated oviduct was increased beyond approximately $7.0 \mathrm{mg} /$ oviduct, a dose-dependent decrease in the NE content of the control oviducts was established. This was consistent with an increased entry of 6-OHDA into the general circulation and, hence, of a greater uptake by tissue which was not perfused. It is of interest to note that the response pattern of uterine tissue was qualitatively similar to that of the oviducts which were not perfused (Table 4).

The observation that $0.5 \mathrm{mg} /$ oviduct of 6 -OHDA caused a $37 \%$ decrease in $\mathrm{NE}$ levels in control oviducts is difficult to resolve with the theory of increasing systemic effect as the dose of 6-OHDA is increased. Unpublished data (T. D. Traylor in Breese \& Traylor, 1970), indicate that multiple doses of small amounts of 6-OHDA may deplete NE to a greater extent than a single large injection. In the light of these data, it may be conjectured that the dose of 0.5 mg/oviduct provides an optimum 6-OHDA concentration to ensure rapid 
uptake into the circulation while larger doses may exert a disruptive effect or trigger diffusion or metabolic barriers.

The demonstration of a graded depletion of $\mathrm{NE}$ in response to given levels of 6-OHDA exhibited by various segments of the rabbit oviduct may be due to differences in sensitivity of those segments to the NE-depleting effect of the drug. Differences in the sensitivity of various organs to the effect of 6-OHDA has been noted (Malmfors \& Sachs, 1968; Thoenen \& Tranzer, 1968). The iris has been found to be a very sensitive organ, while the vas deferens and adrenergic ganglia are largely unaffected by 6-OHDA. Such differences may be due to the different types of post-ganglionic neurones innervating these organs, or to differences in blood perfusion or local tissue 6-OHDA uptake and concentration. It has been shown that, in order to exert its effect, 6-OHDA must be taken up by the adrenergic nerve ending (Malmfors \& Sachs, 1968). It would seem likely that because of the large surface area of the ampulla available for uptake of the drug, the ampullar segments would be as sensitive to 6-OHDA as those of the isthmus. Since perfusion was effected through the uterotubal junction in the ovarian direction at a fairly slow rate of $7 \mu \mathrm{l} / \mathrm{min}$, early inactivation of the drug within the isthmus may have occurred. This, in turn, may have significantly hindered the establishment of a sufficient concentration of active 6-OHDA to deplete NE in segments of the oviduct distal to the uterus.

To be useful as a method for denervation, 6-OHDA should cause maximal $\mathrm{NE}$ depletion in perfused organs while having little or no systemic effect. A dose of $7.0 \mathrm{mg} /$ oviduct appears to approach this ideal. By extrapolation, this dose would deplete NE levels of perfused oviducts by $70 \%$ while exerting no systemic effect. It may be argued that a $70 \%$ depletion is subtotal. However, the histochemical observation that vascular innervation remains largely intact (Goldman \& Jacobowitz, 1971), despite severely depleted tissue NE stores, makes it likely that much of the remaining $30 \% \mathrm{NE}$ is vascular and not associated with the smooth musculature of the oviduct.

\section{AGKNOWLEDGMENTS}

The authors wish to thank Dr R. A. Damon, Jr, Dr D. C. Sharp, III and Miss D. Delahanty for their assistance in this study. Special thanks are given to $\mathrm{Dr}$ J. P. Polidoro for his suggestions and comments during this study. This investigation was supported in part by NIH Contract Grant 2132 and by an NDEA Title IV Fellowship (C.A.E.).

\section{REFERENGES}

Bennett, T., Burnstock, G., Cobb, J. L. S. \& Malmfors, T. (1970) An ultrastructural and histochemical study of the short-term effects of 6-hydroxydopamine on adrenergic nerves in the domestic fowl. Br. 7. Pharmac. Chemother. 38, 802.

Breese, G. R. \& Traylor, J. D. (1970) Effect of 6-hydroxydopamine on brain norepinephrine and dopamine: evidence for selective degeneration of catecholamine neurons. F. Pharmac. exp. Ther. 174, 413.

de Champlain, J. \& Nadeau, R. (1971) 6-Hydroxydopamine, 6-hydroxydopa and degeneration of adrenergic nerves. Fedn Proc. Fedn Am. Socs exp. Biol. 30, 877.

Falck, B. \& OWman, C. (1965) A detailed methodological description of the fluorescence method for the cellular demonstration of biogenic monoamines. Acta Univ. lund. 7, 1. 
Goldman, H. \& Jacobowitz, D. (1971) Gorrelation of norepinephrine content with observations of adrenergic nerves after a single dose of 6-hydroxydopamine in the rat. 7. Pharmac. exp. Ther. 176, 119.

GuYer, M. F. (1953) General statement of methods. In: Animal Micrology, p. 13. University of Chicago Press, Chicago.

Knyihar, E., Ristovsky, K., Kalman, G. \& Csillik, B. (1969) Histochemical and submicroscopical consequences of 6-hydroxydopamine treatment in the rat iris. Experientia, 25, 518.

Maickel, R. P., Cox, R. H., Jr, Saillant, J. \& Miller, F. P. (1968) A method for the determination of serotonin and norepinephrine in discrete areas of rat brain. Int. Fnl Neuro-pharmacol. 7, 275.

Malmfors, T. \& SACHs, C. (1968) Degeneration of adrenergic nerves produced by 6-hydroxydopamine. Eur. Fnl Pharmac. 3, 89.

Mueller, R. A., Thoenen, H. \& Axelrod, J. (1969) Compensatory increase in activity after chemical sympathectomy. Science, N.X. 163, 468.

Steel, R. G. D. \& Torrie, J. H. (1960) Analysis of variance. In: Principles and Procedures of Statistics, p. 99. McGraw-Hill, New York.

Thoenen, H. \& Tranzer, J. P. (1968) Chemical sympathectomy by selective destruction of adrenergic nerve endings with 6-hydroxydopamine. Naunyn-Schmiedebergs Arch. exp. Path. Pharmak. 261, 271.

Tranzer, J. P. \& Thoenen, H. (1968) An electron microscopic study of selective, acute degeneration of sympathetic nerve terminals after administration of 6-hydroxydopamine. Experientia, 24, 155. 